\title{
DAS PAISAGENS NACIONAIS AO CLIMA-MUNDO DA REGIÃO: REFERÊNCIAS NA CONSTRUÇÃO DE IDENTIDADE REGIONAL NA SERRA CATARINENSE
}

\author{
Felipe José Comunello ${ }^{1}$
}

\section{Introdução}

No Brasil verão, praia e calor são referências de identidade nacional. Contudo, com o crescimento econômico dos últimos anos, mais pessoas tem possibilidades de viajar e as viagens para lugares frios estão no rol dessas experiências. Sentir frio em si é algo que não agrada ninguém. É uma experiência carregada de desconforto, sofrimento e preocupação. Em contrapartida, seja para quem viaja a turismo ou quem habita o lugar, há muitas situações onde se pode encontrar conforto perante o frio, estando em recintos aquecidos, alimentando-se com refeições específicas, etc.

Há lugares no Brasil, como as serras gaúcha e catarinense, onde o turismo de inverno é responsável por certo movimento econômico e por muito envolvimento das pessoas que ali vivem em construir suas referências. Os mais interessados no turismo de inverno são os hoteleiros, guias turísticos, políticos locais, dirigentes empresariais, etc., enquanto que o inverno é motivo de grande fardo para muitos habitantes locais, de intermináveis dias e semanas que não passam nunca. Chega a ser motivo de piada para habitantes locais o grande espetáculo promovido por meios de comunicação nos dias em que se esperam os eventos mais raros como a neve. Nestes dias fala-se nisso, positiva ou negativamente, o tempo todo. Por isso, cabe questionar, entre o frio que desagrada e o que agrada o que exatamente acontece? Estariam as pessoas que se agradam pela sensação do frio sendo efetivamente enganadas pelos meios de comunicação e pelo marketing de agências de turismo? Estariam essas pessoas apenas em busca de uma ilusão, a mesma de muitos habitantes locais que promovem as baixas temperaturas, de viver no Brasil à experiência de estar em algum país europeu?

Argumento, com base em pesquisa de campo na Serra Catarinense, e em um diálogo com alguns autores que discutem as relações cultura e natureza, não se tratarem efetivamente de enganação ou ilusão o que acontece entre o frio desagradável e o frio agradável. Mas, de modos de percepção os quais envolvem desde o enquadramento do turismo de inverno nessas regiões como o exótico dentro do próprio país em um tempo homogêneo da nação (Anderson, 1993) demarcado em determinado período do ano (o

\footnotetext{
${ }^{1}$ Universidade Federal do Rio Grande do Sul, Brasil.
} 
tempo de inverno, propriamente dito) a as vivências do inverno como o não exótico, referências para a construção de identidades regionais, em outros tempos constituídos no entre-lugar (Bhabha, 1998).

Estes outros tempos destoam do tempo homogêneo da nação, no qual paisagens típicas (como as relacionadas às praias e ao calor) são um componente da construção da identidade nacional (Thiesse, 1999). Neste aspecto em particular acompanho a discussão do antropólogo britânico Tim Ingold (2000; 2011), a qual trata de repensar o conceito de paisagem (landscape) e até mesmo substituí-lo por outro mais adequado. Ingold (2011) sugere que o conceito de paisagem está relacionado à percepção do mundo terrestre, sendo necessário outro que incorpore o céu e possibilite uma maior compreensão do mundo como um todo. Enfim, que possibilite a compreensão do climamundo (weather-world).

Discuto estas sugestões de Tim Ingold em um movimento que a partir de uma situação específica, a repercussão da ocorrência de neve em agosto de 2010 na Serra Catarinense, onde discuto o tempo da nação e os tempos particulares, faço um debate um pouco mais teórico em torno da questão da paisagem e por último discuto o climamundo do joaquinense, um tipo ideal de personagem da Serra Catarinense ${ }^{2}$. Faço isto por meio da trajetória de um escritor local, Joaquim Anacleto, quem expressa em grande medida as opiniões de uma classe que conduz o poder local. Joaquim Anacleto vive hoje em seu sítio, é dentista aposentado, foi prefeito de São Joaquim em duas ocasiões e é membro de uma família reconhecida por sua importância no campo das artes e das letras no município. Anacleto traz à baila a ideia de que para o joaquinense a neve não é exótica e que enquanto todo o brasileiro entende de futebol, o joaquinense entende de tempo.

\section{A paisagem branquinha, os caminhos da neve e a janela de @ valdson}

\footnotetext{
"Esta região de Santa Catarina é conhecida como caminhos da neve. Quem sonha em conhecer a paisagem branquinha deve seguir essa rota. São $227 \mathrm{~km}$ de Florianópolis até São Joaquim (grifos meus)"3.
}

\footnotetext{
${ }^{2}$ Este artigo faz parte de uma discussão realizada em um estágio inicial da minha pesquisa de doutorado. O doutorado foi iniciado no ano de 2010.

3 MEURER, Kíria. Neve atrai milhares de turistas para a serra catarinense. Jornal Hoje, 05/08/10. Disponível em http://g1.globo.com/videos/jornal-hoje/v/neve-atrai-milhares-de-turistas-para-a-serracatarinense/1313340/\#/Edições/20100805/page/1 Acesso em 11/10/10.
} 
Assim uma repórter narrava um roteiro para conhecer o sul do Brasil, anunciado pela âncora de um dos principais jornais da Rede Globo, na primeira semana de agosto de 2010, quando foi registrada a ocorrência de neve em várias cidades de Santa Catarina e Rio Grande do Sul. Os caminhos da neve e a paisagem branquinha eram ilustrados por imagens de automóveis, casas, campos, estradas, ruas, praças, etc., cobertos de neve. Também apareciam pessoas, destacadamente adultos, brincando e saudando o fenômeno. No geral, a aparência das pessoas era de felicidade com a experiência, sem sermos informados de possíveis complicações como acidentes de trânsito, problemas de abastecimento de água, etc. Sendo assim, a paisagem branquinha era efetivamente algo que destacava a atenção, tanto de repórteres como das pessoas presentes na reportagem, como algo positivo.

A rota narrada pela repórter foi ilustrada por uma montagem que compreendia os municípios de Santa Cecília, Ponte Alta, Orleans, Urussanga, Anita Garibaldi, Bom Jardim da Serra, Urupema, Urubici e São Joaquim. É pertinente notar que o município de São Joaquim aparece em tal reportagem como o ponto de chegada para quem deseja conhecer a neve no sul do Brasil, ao passo que a repórter menciona outras cidades para serem conhecidas nas proximidades. Não menos importante é o indicativo de Florianópolis, capital do estado, como o ponto de partida. O que pode ser lido como um indício de que essa tende ser a maneira de falar para o país sobre um lugar frio. Efetivamente, são duas as rotas geralmente mais prováveis de serem realizadas de automóvel abrangendo a rota indicada pela reportagem, tendo Florianópolis como referência, mas também Curitiba (Figuras 01 e 02). 


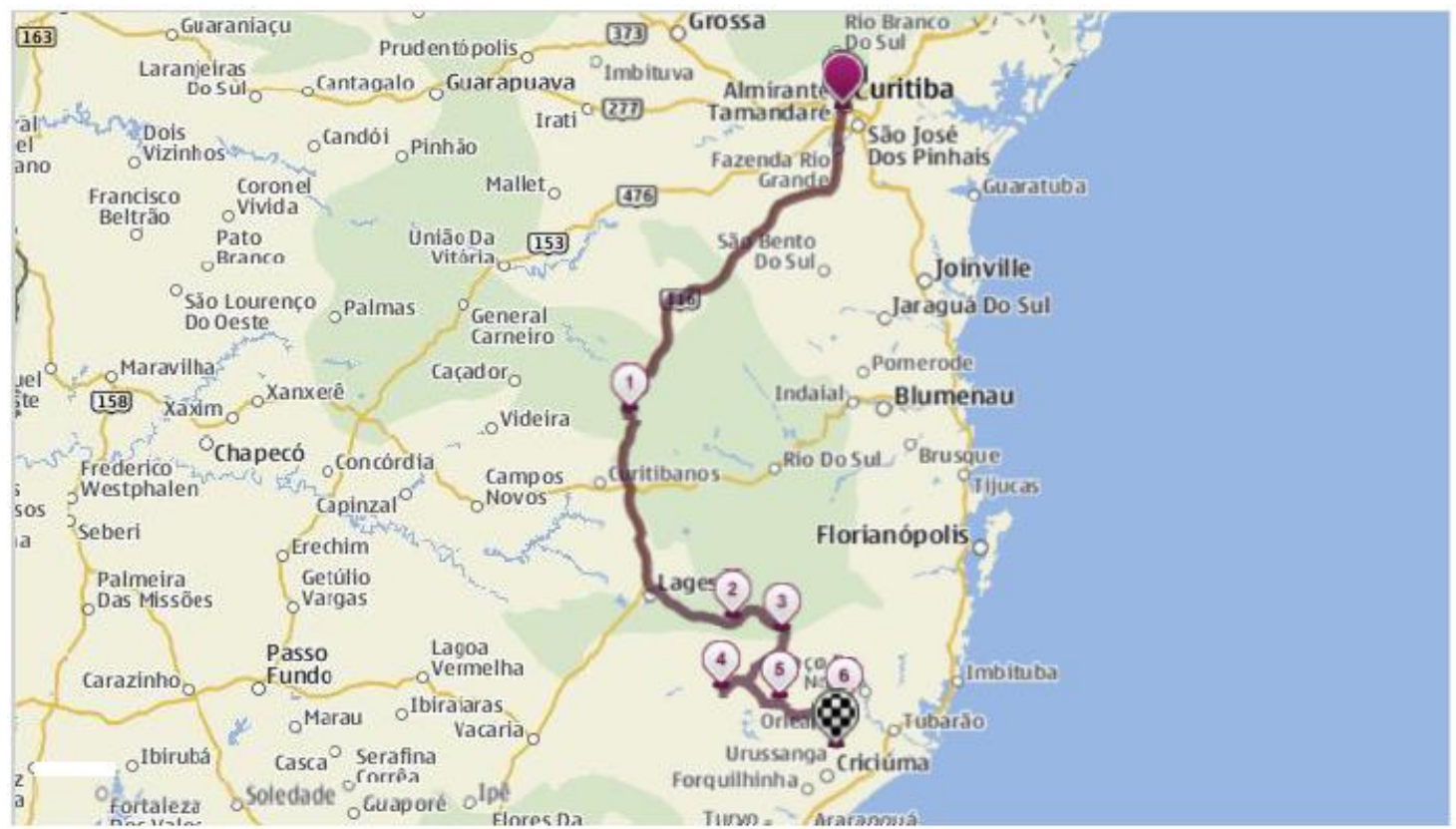

Figura 01: Rota para quem sai ou passa por Curitiba. Santa Cecília (1), Urupema (2), Urubici (3), São Joaquim (4), Bom Jardim da Serra (5), Orleans (6), Urussanga (chegada). No caminho, está Lages entre Santa Cecília e Urupema, local onde normalmente não neva, mas tem razoável oferta de hotéis e restaurantes para receber os viajantes.

Fonte: http://maps.nokia.com - Acesso em 16/09/2011.

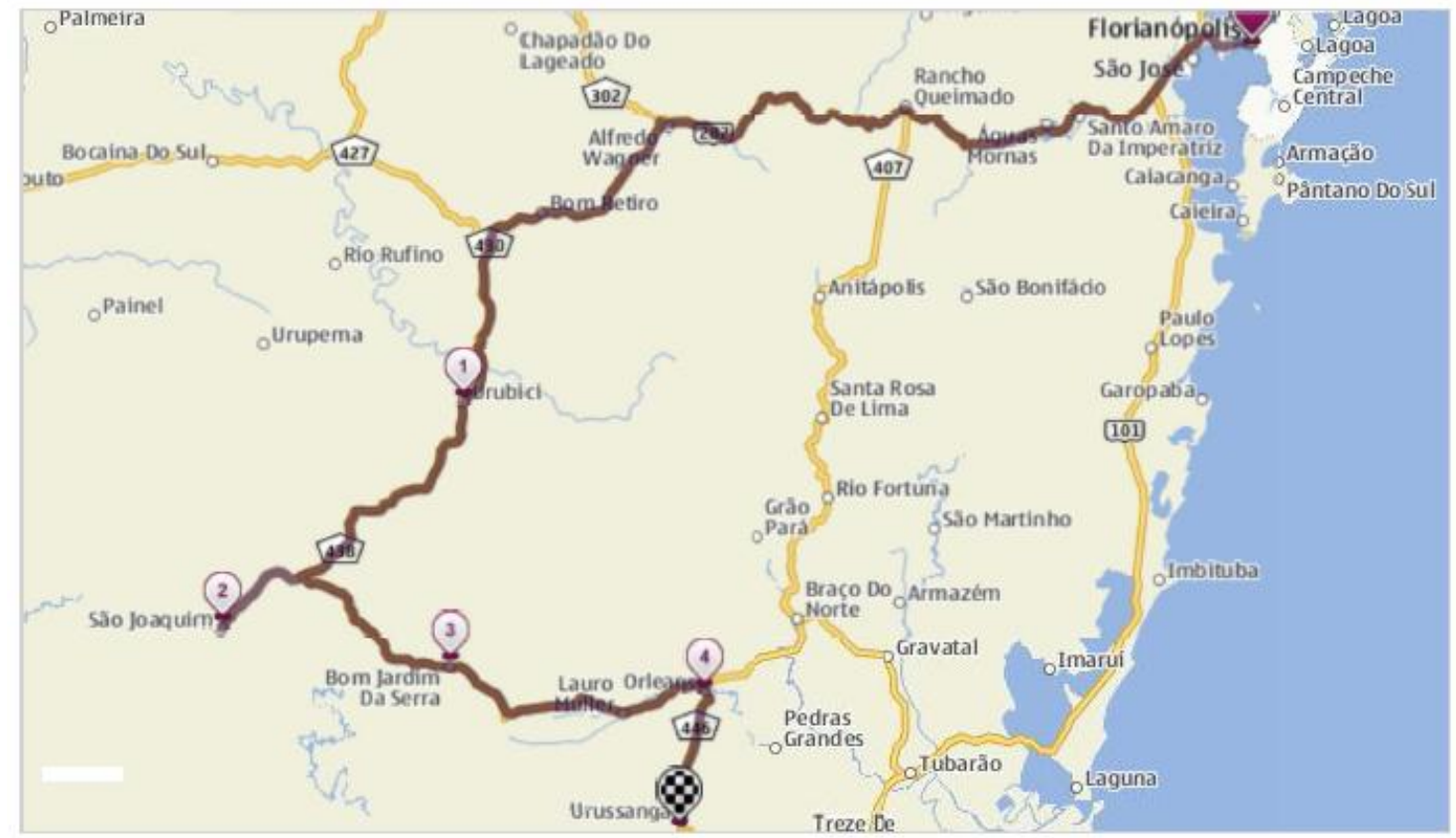

Figura 02: Rota para quem sai ou passa por Florianópolis. Urubici (1), São Joaquim (2), Bom Jardim da Serra (3), Orleans (4), Urussanga (chegada).

Fonte: http://maps.nokia.com - Acesso em 16/09/2011. 
Abaixo destaco algumas imagens encontradas em veículos de comunicação de grande circulação em Santa Catarina e no país (Figuras 03, 04, 05 e 06). São imagens que ilustram a alegria das pessoas perante a experiência de presenciar a ocorrência de neve. Mas, também indicam o movimento por rotas, possivelmente as mencionadas acima, que levam aos lugares que são referência. Nas imagens selecionadas, destaca-se o município de Urubici, frequentemente lembrado como uma referência de lugar frio e o município mais próximo à Florianópolis dentre os que comumente são compreendidos como pertencentes a Serra Catarinense.

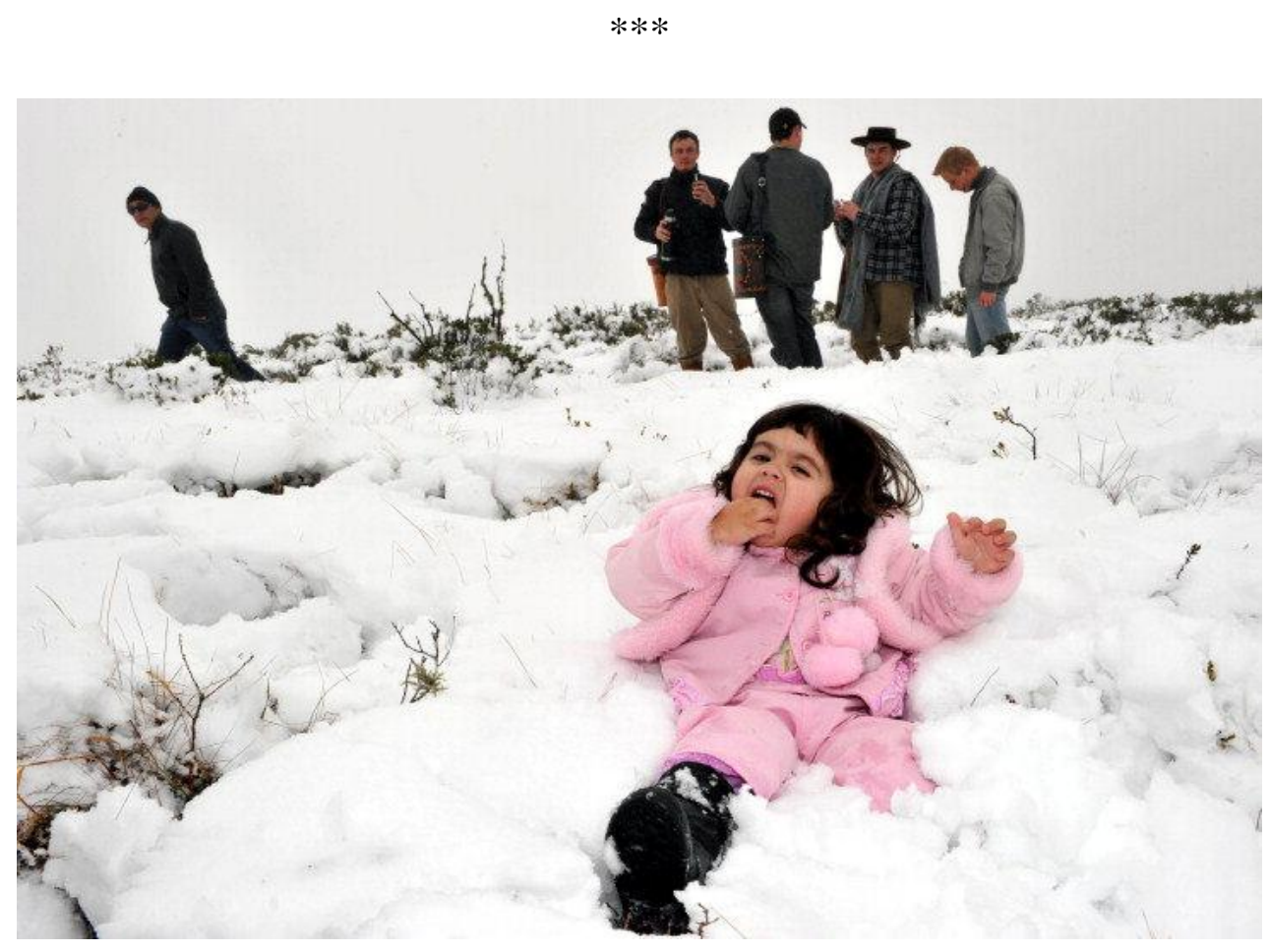

Figura 03: Turistas aproveitam o possível último dia de neve em Urubici.

Fonte: Diário Catarinense de 05 de agosto de $2010^{4}$.

\footnotetext{
${ }^{4}$ Disponível em: http://www.clicrbs.com.br/diariocatarinense/jsp/default.jsp?uf=2\&local=18\&section=Geral\&newsID=a29 95870.xml - Acessado em 19/10/2011.
} 


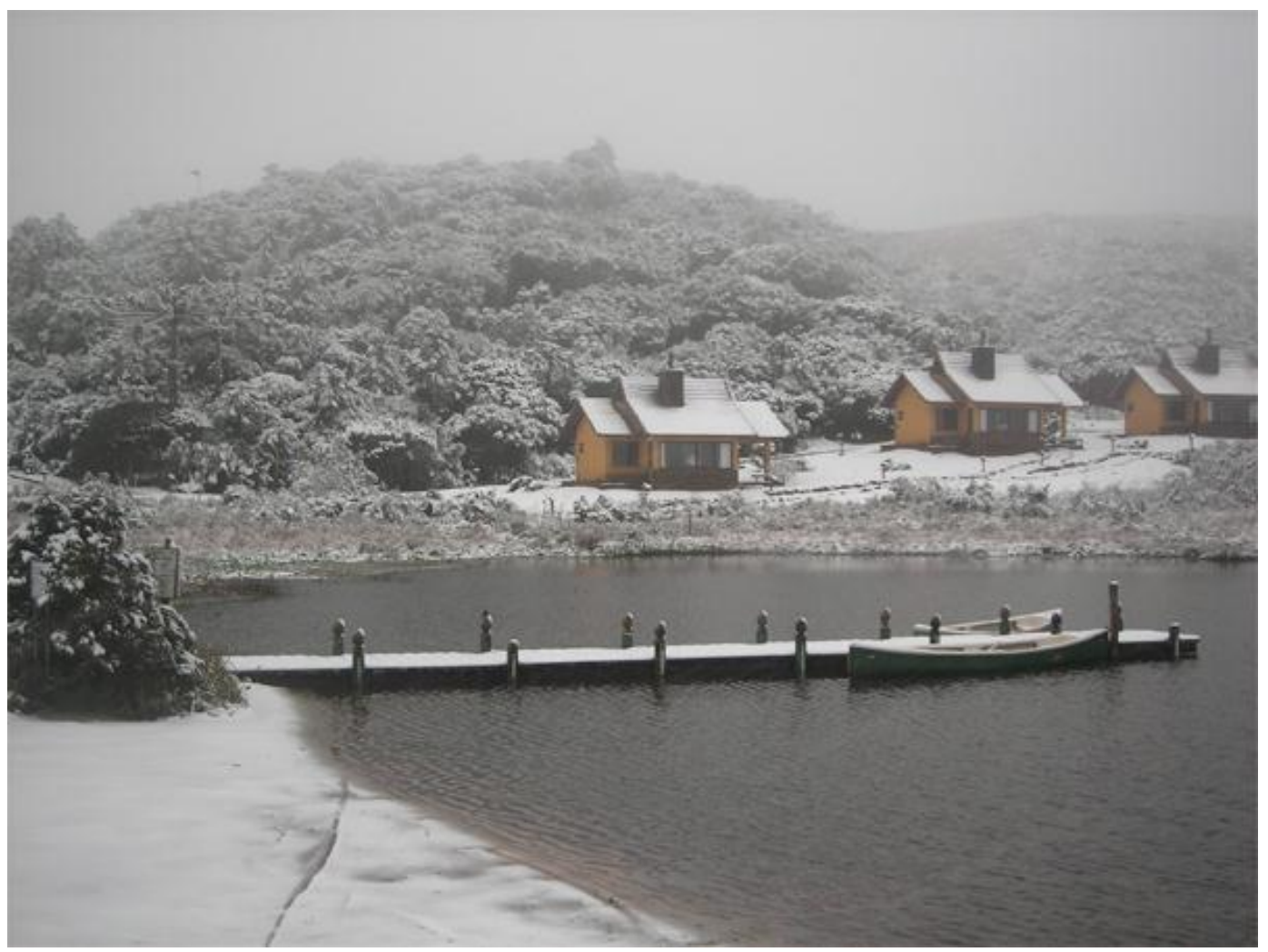

Figura 04: Chalés em um hotel próximo de São Joaquim no dia 04 de agosto de 2010. Fonte: Blog Estela Benetti no Clic RBS ${ }^{5}$.

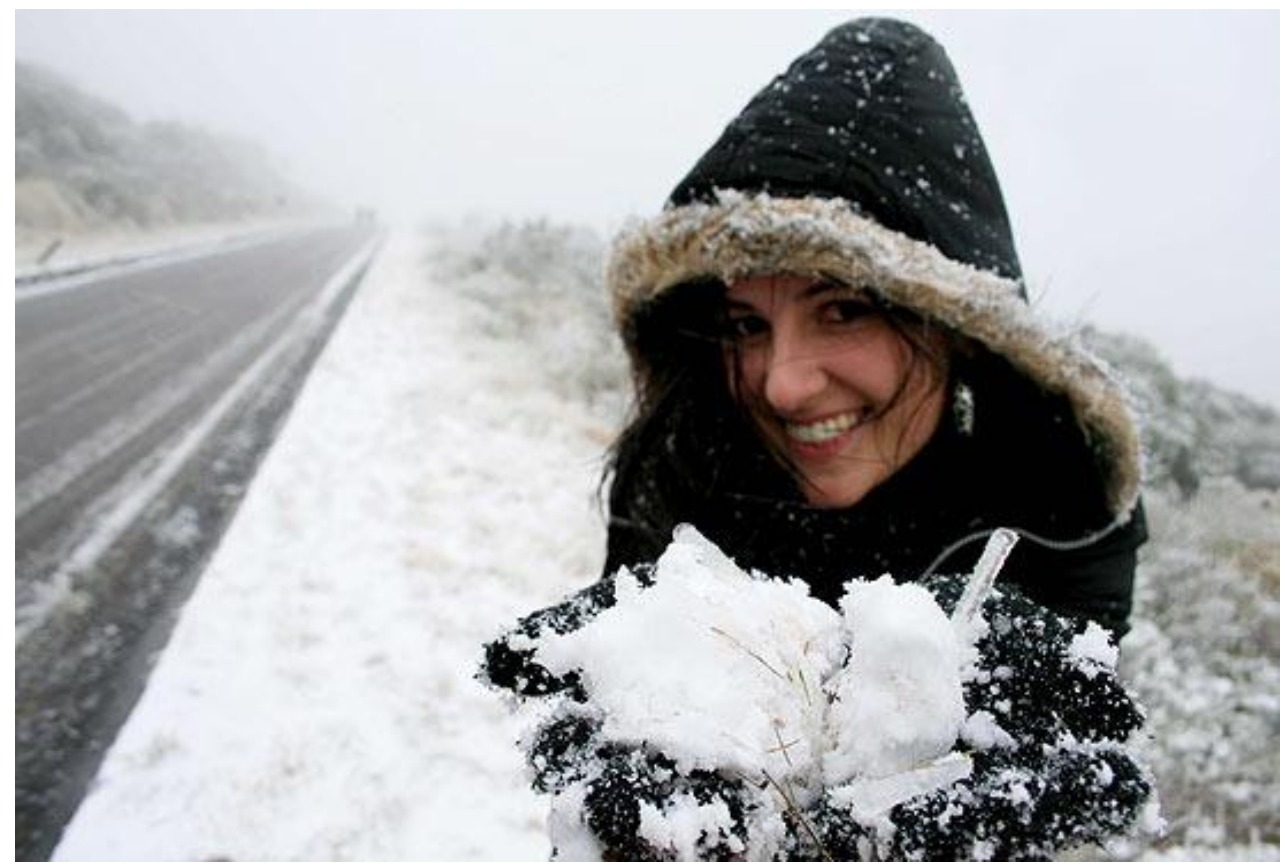

Figura 05: Flocos de neve cobrem estrada que leva ao Morro da Igreja, em Urubici, na serra catarinense, na quarta-feira.

Fonte: Folha de São Paulo de 05 de agosto de $2010^{6}$.

\footnotetext{
${ }^{5}$ Disponível em http://wp.clicrbs.com.br/estelabenetti/2010/08/06/marketing-da-neve-para-a-serra-de-sc/ Acesso em 13/10/210.
} 


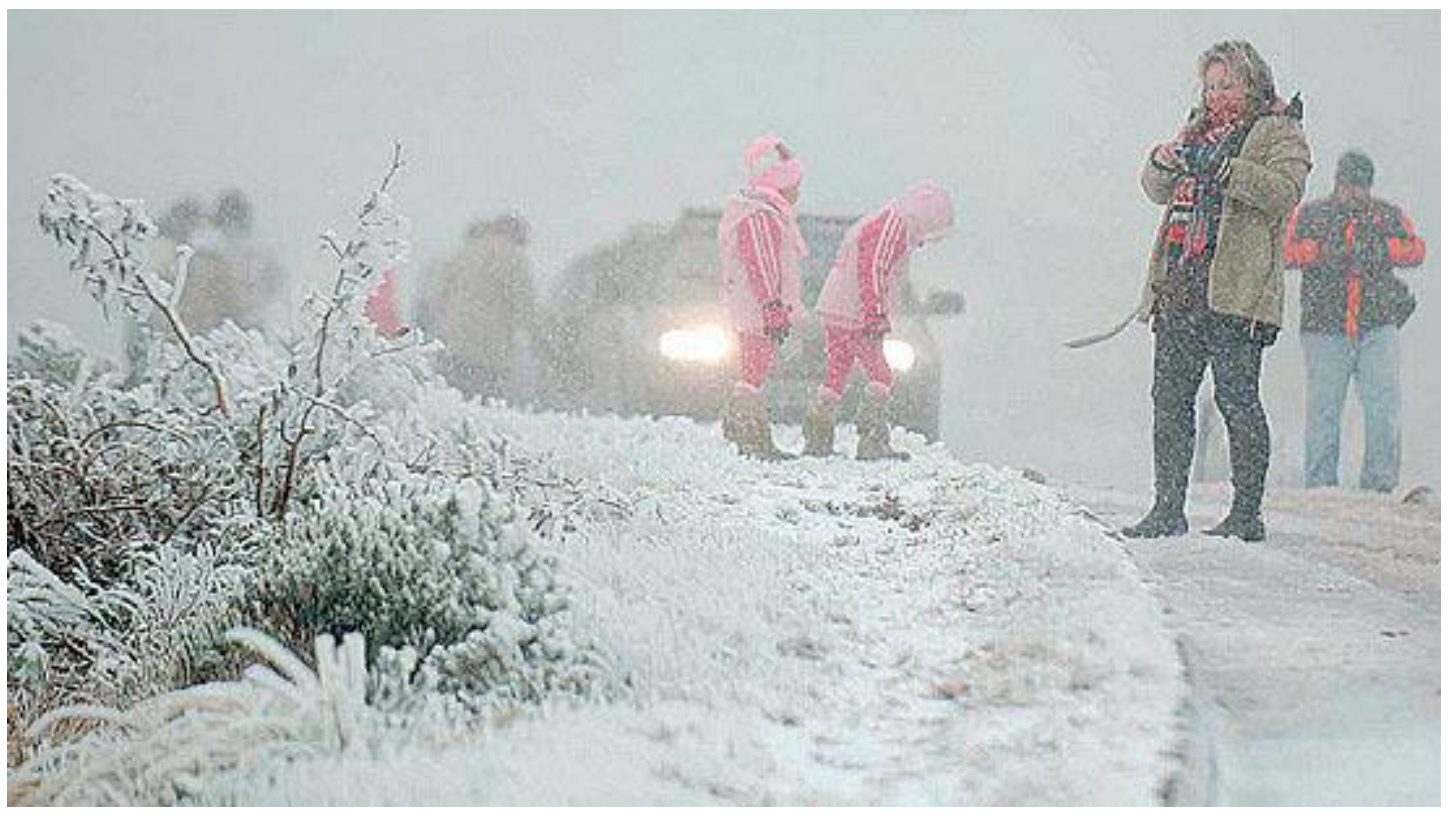

Figura 06: Neve em estrada em Urubici (SC) na quarta, quando nevou em 9 cidades de SC; Urubici voltou a ter neve hoje.

Fonte: Folha de São Paulo de 05 de agosto de $2010^{7}$.

No dia anterior a referida reportagem, acompanhei ao vivo o fenômeno

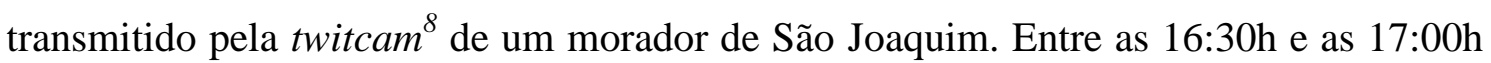
do dia 04 de agosto eram aproximadamente 5 mil e 6 mil observadores (viewers), onde cada um poderia estar representando uma ou mais pessoas observando as imagens. No twitter $^{9}$, São Joaquim chegou a permanecer por algum tempo nos trending topics ${ }^{10}$, denotando a importância que a neve ocorrendo nessa cidade alcança no país. As

\footnotetext{
${ }^{6}$ Disponível em http://www1.folha.uol.com.br/cotidiano/778249-urupema-sc-acumula-30-cm-de-neveminima-no-estado-chega-a--5c.shtml - Acessado em 19/10/11.

${ }^{7}$ Disponível em http://www1.folha.uol.com.br/cotidiano/778191-volta-a-nevar-na-manha-de-hoje-emurubici-sc-rs-tambem-tem-chance-de-neve.shtml - Acessado em 19/10/11.

8 "Twitcam é um serviço vinculado ao Twitter, microblogging e serviço de mídia social, que permite aos seus usuários enviarem vídeos ao vivo através de uma câmera conectada ao seu computador. Funciona como se fosse um programa de televisão ao vivo, onde as pessoas participam "Twittiando" sobre o serviço". Disponível em http://pt.wikipedia.org/wiki/Twitcam - acessado em 25/10/2011.

9 "Twitter é uma rede social e servidor para microblogging, que permite aos usuários enviar e receber atualizações pessoais de outros contatos (em textos de até 140 caracteres, conhecidos como "tweets"), por meio do website do serviço, por SMS e por softwares específicos de gerenciamento". Disponível em http://pt.wikipedia.org/wiki/Twitter - acessado em 25/10/2011.

10 "Os Trending Topics ou TTs são uma lista em tempo real dos nomes mais postados no Twitter pelo mundo todo. Valem para essa lista as hashtags (\#) e nomes próprios". Disponível em http://pt.wikipedia.org/wiki/Twitter - acessado em 25/10/2011.
} 
imagens captados pelo usuário @valdson, circularam por vários veículos de comunicação (Figura 07) ${ }^{11}$.

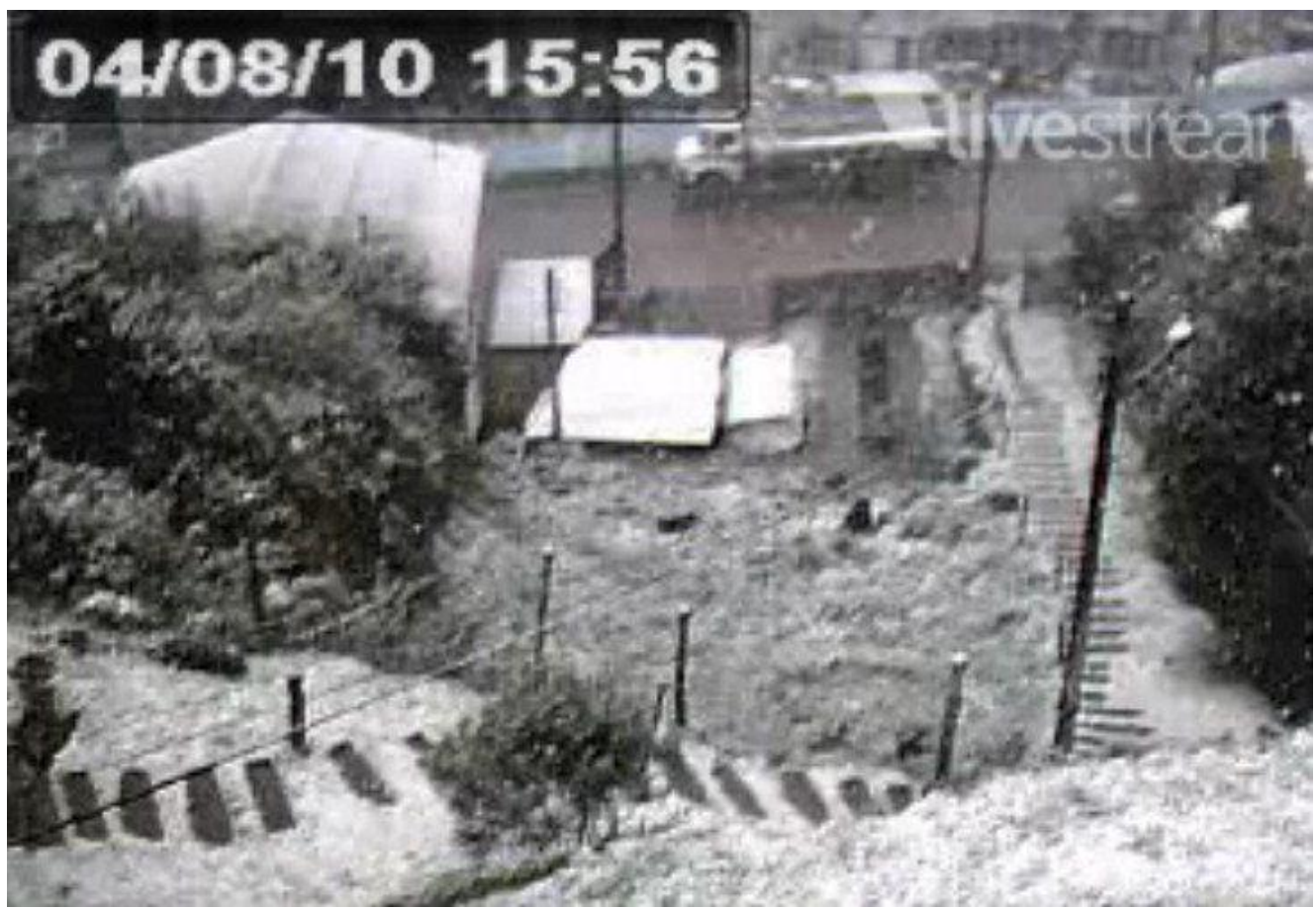

Figura 07: Neve é filmada ao vivo por em São Joaquim. Fonte: Diário Catarinense de 04 de agosto de $2010^{12}$.

Mais do que a quantidade de observadores espalhados pelo país, atentos ao fenômeno ocorrendo em São Joaquim, era interessante a maneira como as pessoas se referiam a ele. No geral, a grande maioria reproduzia para seus contatos o acontecido em São Joaquim. Mas, muitas pessoas também aproveitavam para manifestar surpresa com relação ao fenômeno, fantasiar seus desejos caso estivesse presente no local, e muitos manifestavam o desejo de que ocorresse em sua cidade. Nesse último aspecto,

\footnotetext{
${ }^{11}$ Valdson Godoy Ricardo é professor de informática em São Joaquim. Imagens e maiores informações disponíveis em http://saojoaquimonline.com.br/joaquinense-se-torna-famoso-por-exibir-neve-ao-vivovia-twitcam - acessado em 25/10/2011. O fato foi noticiado, por exemplo, na TV Brasil, ver http://www.youtube.com/watch?v=dJ6M70d959A - acessado em 25/10/2011.

${ }^{12}$ Disponível em

http://www.clicrbs.com.br/diariocatarinense/jsp/default.jsp?uf=2\&local=18\&section=Geral\&newsID=a29 94178.htm - Acesso em 19/10/2011.
} 
destacavam-se moradores das cidades de Curitiba e Blumenau, os primeiros anunciando a previsão de neve para a cidade, "Simepar informa que vai nevar essa madrugada em Curitiba!" e, os segundos desejando "queremos neve em Blumenau!"13.

Estas apostas e desejos dos usuários do twitter na previsão de neve em suas cidades me remetem para a noção de comunidade imaginada de Benedict Anderson (1993). Para Anderson (1993) o jornal e o romance são as duas formas de criação imaginária que floresceram na Europa durante o século XVIII, e proporcionaram meios técnicos para representar a nação. O twitter como meio de comunicação, mais interativo do que o jornal, colocava desconhecidos vivendo ou na expectativa de viver o fenômeno típico de inverno ao mesmo tempo. Como no romance em que "(...) el hecho de que estos actos se realicen a la misma hora y en el mismo día, pero con actores que podrían estar en gran medida inconscientes de la existencia de los demás, revela la novedad de este mundo imaginado, evocado por el autor en las mentes de sus lectores (Anderson, 1993: 48)".

Anderson (1993) trabalha com a idéia de Walter Benjamin, de tempo homogêneo e vazio da nação moderna, onde a simultaneidade é marcada pela coincidência temporal, marcada pelo relógio e pelo calendário. Seria esse tempo homogêneo e vazio que propicia a formação da comunidade imaginada da nação. Uma comunidade imaginada em que muitos se vejam como um, representados pela mesma bandeira, tendo os mesmos direitos, etc. Entretanto, o jornal de alcance nacional, de uma das grandes redes de televisão do país, mostra o que acontece em um dia de inverno em uma parte do Brasil. É fato que muitos poderiam seguir, desde que dispondo de meios para tal, o caminho sugerido pelo jornal. Mas, se vimos tuiteiros de Curitiba e Blumenau imaginando a neve em suas cidades, para moradores de outros lugares do país, especialmente aqueles que estão localizados fora das regiões sul e sudeste, vivenciarem essa experiência em suas cidades é menos imaginável. Do mesmo modo, a distância física pode impedir a experiência de moradores de outras regiões de se deslocarem para o caminho indicado pelo jornal. Não apenas pela distância em si, mas porque as distâncias entre os diferentes lugares são também expressão de práticas, de vivências, de memórias de vida diferentes.

\footnotetext{
${ }^{13}$ Essas frases eram repetidas por diversos usuários através da ferramenta Retweet e agrupadas pelo twitter na hashtag \#neve. Nesse dia outras hashtags que agrupavam comentários sobre o fenômeno em Santa Catarina eram \#serracatarinense, \#saojoaquim e \#serraSC.
} 
Com isso, pode-se indagar a idéia de tempo homogêneo e vazio, utilizada por Benedict Anderson (1993) na noção de comunidade imaginada de representação da nação. Como procurei demonstrar com o caso da ocorrência da neve no sul do Brasil, há uma ambivalência que se instaura na comunidade imaginada. Homi Bhabha (1998) se refere a um tempo duplo e cindido da representação nacional, onde às margens da modernidade emerge o arcaico. Um espaço liminar de significação, marcado por discursos de minorias, por histórias heterogêneas de povos em disputa, por autoridades antagônicas e locais tensos de diferenças culturais. Um entre-lugar, introduzido pelo performático.

Os fragmentos, retalhos e restos da vida cotidiana devem ser repetidamente transformados nos signos de uma cultura nacional coerente, enquanto o próprio ato da performance narrativa interpela um círculo crescente de sujeitos nacionais. $\mathrm{Na}$ produção da nação como narração ocorre uma cisão entre a estratégia continuísta, cumulativa, do pedagógico e a estratégia repetitiva, recorrente, do performático. É através deste processo de cisão que a ambivalência conceitual da sociedade moderna se torna o lugar de escrever a nação (Bhabha, 1998: 207).

O que pôde ser visto pela janela de Valdson no twitter, performatiza uma narrativa que descontinua a narrativa midiática que apresenta a paisagem branquinha. Valdson apresentou um registro que é o de alguém que está em sua casa abrigado do frio, vendo o caminho sendo coberto por neve e provavelmente supondo encontrar dificuldades para enfrentá-lo caso desejasse sair de casa. Registro que destoa daqueles destacados nos grandes veículos de comunicação, que trazem a alegria das pessoas com a neve. Porém, como pensar o entre-lugar, que para Homi Bhabha é o local da cultura, diante destas manifestações que trazem consigo o frio, a neve e outros fenômenos naturais?

\section{Paisagem?}

Para discutir tal questão, a noção de paisagem é incontornável, pois é de uso corrente nos meios de comunicação, como também é objeto de muitas discussões na academia. Um autor que se ocupou do conceito de paisagem foi Georg Simmel. Para ele, a paisagem seria unidade perceptível, tendo como suporte principal a Stimmung.

Referindo-se ao homem, entenda-se por esta palavra a unidade que dá cor constantemente ou num dado momento à totalidade dos seus conteúdos psíquicos, unidade que nada constitui de singular em si e não adere, em muitos casos, a qualquer elemento singular facilmente indicável, mas que não obstante representa o geral onde se encontram num determinado momento, todas estas particularidades. 
Ora, o mesmo vale para a Stimmung da paisagem: ela penetra todos os detalhes da mesma sem que se possa tornar um só deles responsável por ela: cada um participa de uma maneira pouco claramente definida - mas ela não existe mais exteriormente a esses aportes como se não se compõe da sua soma. (Simmel, 1996: 21)

Para melhor compreender o que seja a Stimmung da paisagem, Georg Simmel trata de questionar como se pode encontrar a sua formação no momento que se passa por um conjunto de pedaços soltos para a unidade. E, além disso, trata-se de pensar se a Stimmung é um estado psíquico, que não reside nas coisas exteriores ausentes de consciência. Georg Simmel procura resolver isso admitindo que a paisagem é instaurada pela alma do espectador. Assim, a unidade perceptível e a Stimmung da paisagem seriam componentes de um mesmo meio, exprimível em dois. Uma solução um pouco diferente pode ser encontrada na obra de Gregory Bateson. Ao contrário de Simmel, que escreveu no início do século XX, Bateson está situado em um contexto no qual as indagações que motivam a "questão ambiental” começam a surgir.

We face a world which is threatened not only with disorganization of many kinds, but also with the destruction of its environment, and we, today, are still unable to think clearly about the relations between an organism and its environment. What sort of a thing is this, which we call "organism plus environment"? (Bateson, 1987: 318)

Diante desta afirmação Bateson abria possibilidades para pensar as relações entre o organismo e o ambiente. Contudo, discutir em torno do que se trata "organismo mais ambiente" é algo muito amplo e o autor propõe seguir uma fórmula do filósofo Korzybiski, que intitula a conferência na qual o mesmo explanava ${ }^{14}$. A fórmula a que se

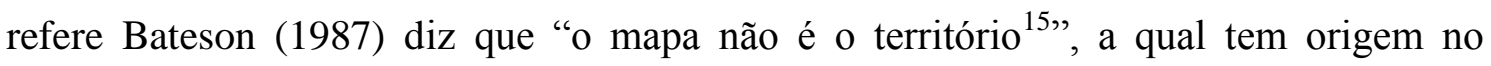
pensamento filosófico europeu dos últimos dois mil anos. Nesta história, Bateson argumenta que se estabeleceu uma dicotomia entre Pitágoras e seus predecessores, que tomou a forma de análise do que é feito a terra, a água e etc. (substance), ou análise de seus modelos (patterns). Nesta controvérsia os seguidores de Pitágoras (the Pythagoreans) sempre se encontraram numa posição inferior até o auge da argumentação no fim do século XVIII, quando uma teoria Pitagoreana da evolução foi descartada - a qual implicava a existência da Mente $(\text { Mind })^{16}$.

\footnotetext{
${ }_{15}^{14}$ A Nineteenth Annual Korzybski Memorial Lecture, delivered January 9, 1970.

15 "(...) the map is not the territory (idem, p. 318)"

${ }^{16}$ A Mente (Mind) a que se refere Bateson, pode ser equiparada a alma de que fala Simmel.
} 
Segundo Bateson, a teoria evolucionista do fim do século XVIII, a teoria Lamarckiana, subverteu o que se acreditava ser a organização do mundo orgânico até então, hierárquico na estrutura, com a Mente no topo. Com esta mudança a Mente precisava ser explicada e foi isto que Lamarck fez, criando a psicologia comparativa. Nisto, Mente e modelos foram empurrados para fora do pensamento biológico por Darwin, entre outros. Segundo Bateson, foi empiricamente provado que Darwin cometeu o erro de achar que a unidade de sobrevivência sob a seleção natural era o individuo, a família ou um grupo similar de co-específicos. Isto porque, se um organismo trabalha pela sua própria sobrevivência e pensa que isto é a maneira para selecionar quais passos tomar, acaba destruindo seu próprio ambiente. Na verdade, segundo Bateson os geneticistas de populações corrigiram isto parcialmente, a unidade de evolução não é homogênea, é muito variada. "The unit of survival is a flexible organism-in-it-environment (Bateson, 1987: 320)".

Em grande medida, esta é a justificativa e a explicação para se tomar o "organismo mais ambiente" e Bateson o faz retomando a discussão anterior a Lamarck, já com os aportes da teoria da informação e a cibernética. E no caminho que Bateson percorre é preciso pensar a unidade da mente, retomando a questão do mapa e do território, para se perguntar.

\footnotetext{
"What is it in the territory that gets onto the map?" We know the territory does not get onto the map. That is the central point about which we here are all agreed. Now, if the territory were uniform, nothing would get onto the map except its boundaries, which are the points at which it ceases to be uniform against some larger matrix. What gets onto the map, in fact, is difference, be it a difference in altitude, a difference in vegetation, a difference in population structure, difference in surface, or what-ever. Differences are the things that get onto a map (Bateson, 1987: 320).
}

E a diferença não é uma coisa ou um evento, é um conteúdo abstrato. A diferença entre o papel e a madeira, por exemplo, não está nem no primeiro e nem no segundo. "Difference travels from the wood and paper into my retina. It then gets picked up and worked on by this fancy piece of computing machinery in my head (Bateson, 1987: 320)". Então, Bateson sugere que a palavra "ideia" no seu sentido mais elementar é sinônimo de "diferença". Bateson exemplifica esta sugestão com uma asserção de Kant, para quem o ato estético mais elementar é a seleção de um fato. Nisso, um pedaço de giz tem um número infinito de fatos potenciais. Um pedaço de giz nunca pode entrar num processo mental devido sua infinitude. Por isso, os receptores 
sensoriais selecionam fatos fora do pedaço de giz, os quais tornam-se, na moderna terminologia, informação. No lugar de fatos, Bateson sugere colocar diferenças (no caso, entre a localização do pedaço de giz, ou outra molécula, e as localizações onde ele poderia estar).

In fact, what we mean by information - the elementary unit of information-is a difference which makes a difference, and it is able to make a difference because the neural pathways along which it travels and is continually transformed are themselves provided with energy. The path-ways are ready to be triggered. We may even say that the question is already implicit in them. (Bateson, 1987: 321)

Bateson alerta para um contraste importante entre os caminhos da informação dentro do corpo e fora do corpo. Isto porque, Bateson propõe deixar de lado a ideia de "mundo físico" externo "mundo mental", e admitir que a Mente seja imanente no ecossistema. Em certa medida, Tim Ingold retoma as ideias de Bateson e propõem alguns conceitos, os quais têm retrabalhado ao longo do tempo. No quadro da "perspectiva da habitação" (dwelling perspective), buscando trabalhar a temporalidade da paisagem (landscape), Ingold propôs um caminho alternativo as visões naturalistas e culturalistas.

\footnotetext{
I believe that such a focus might enable us to move beyond the sterile opposition between the naturalistic view of the landscape as a neutral, external backdrop to human activities, and the culturalistic view that every landscape is a particular cognitive or symbolic ordering of space. I argue that we should adopt, in place of both these views, what I have called a 'dwelling perspective', according to which the landscape is constituted as an enduring record of - and testimony to - the lives and works of past generations who have dwelt within it, and in so doing, have left there something of themselves (Ingold, 2000: 189).
}

Argumentava Ingold que a paisagem (landscape) não é "solo" (land), nem "natureza" (nature) e nem "espaço" (space). Enquanto land é quantitativo e homogêneo, landscape é qualitativo e heterogêneo. Enquanto nature em um sentido específico tem como fundação ontológica o mundo "out there" que quem o percebe reconstrói mentalmente, landscape “(...) becomes a part of us, just as we are a part of it (Ingold, 2000: 191)” " “(...) in a landscape, each component enfolds within its essence the totality of its relations with each and every other (idem)". Enquanto space é mapeado, como se todos fôssemos cartógrafos e registrássemos inputs sensoriais de múltiplos pontos de observação em uma imagem processada por nossa inteligência de tudo que está a nossa volta, em landscape a distancia entre dois pontos A e B é 
experienciada movendo o corpo de um lugar a outro, gradualmente mudando as perspectivas sobre a rota. "Thus whereas with space, meanings are attached to the world, with the landscape they are gathered from it. Moreover, while places have centres - indeed it would be more appropriate to say that they are centres - they have no boundaries (idem, p. 192)".

Por outro lado, em uma caracterização positiva da paisagem, argumentava Ingold que a mesma é o mundo como conhecido por aqueles que nele moram, habitando seus lugares e viajando pelos caminhos que os conectam. Mas, essa caracterização, por vezes é confundida com ambiente, o que o autor trata de diferenciar, argumentando que ambiente tem o mesmo sentido de natureza, algo separado da humanidade. Neste sentido, o ambiente é muitas vezes visto em termos de função, que permite aos humano e não-humanos certas capacidades e projetos de ação. Já o conceito de paisagem coloca ênfase na forma, da mesma maneira que o conceito de corpo enfatiza a forma ao invés da função de uma criatura viva. Com isso, como organismo e ambiente, corpo e paisagem são termos complementares. Mas a paisagem não é preparada anteriormente para uma criatura ocupar. Ambas as formas são geradas em e através de um processo de revelação de um campo total de relações que atravessa a interface entre organismo e ambiente, um processo de embodiment (movimento de incorporação, não de inscrição). E esse movimento envolve repensar também a temporalidade da paisagem.

Contudo, praticamente dez anos depois, Tim Ingold (2011) reformula seus conceitos sobre como o mundo é percebido, argumentando que a noção de paisagem (landscape) está relacionado a suposição de que o mundo é terrestre. Segundo o autor, a incorporação do conceito de paisagem na linguagem de painterly depiction a errar as conotações do sufixo -scape para um particular "regime escópico" de observação detalhada e desinteressada. Com isso, gerações de acadêmicos tem se enganado com o conceito de paisagem, por uma superficial semelhança entre scope e scape, que não tem fundamento etimológico. Scope vem do grego skopos, do qual deriva o verbo skopein, "to look", e, Scape vem Inglês Antigo sceppan ou skyppan, que significa "to shape". Este regime escópico particular tornou-se firmemente arraigado na história da arte moderna. Landscape veio a ser identificada com um cenário e com uma descrição de arte que deve ver o mundo em uma tela, a qual apesar de pouco reconhecida, frequentemente inclui o céu. 
Tim Indolg discute com o psicólogo James Gibson, quem insiste que percebemos objetos da superfície, mais ou menos sólidos, do e no chão. Tomando como exemplo alguém que esteja caminhando em uma floresta, olha para cima e vê entre buracos entre o dossel de folhas, pergunta-se Ingold, se pode o ambiente ter buracos, deve ter o céu uma superfície onde um dia nublado desanuvia-se e se as nuvens isoladas estão suspensas no vazio. Ingold procura responder tais questões com outro exemplo, do Ursinho Puff que sonhava que pendurado em um balão poderia enganar as abelhas, passando-se por uma nuvem, quando realmente estava atrás do seu mel. Porém, logicamente, as abelhas não são estúpidas a esse ponto. Na interpretação deste exemplo, Ingold critica Gibson, para quem Puff somente estaria fugindo com o balão. Segundo Ingold, Gibson insiste em não ver a luz propriamente, mas a superfície das coisas iluminadas pelas coisas. Ingold propõem não separar a vista da luz.

Rather than thinking of ourselves only as observers, picking our way around the objects lying about on the ground of a ready-formed world, we must imagine ourselves in the first place as participants, each immersed with the whole of our being in the currents of a world-in-formation: in the sunlight we see in, the rain we hear in and the wind we feel in. Participation is not opposed to observation but is a condition for it, just as light is a condition for seeing things, sound for hearing them, and feeling for touching them. (Ingold, 2011: 129)

Em outro exemplo, Ingold ressalta como os antropólogos e arqueólogos pouco se têm preocupado com o clima (weather). A questão surgiu a partir de uma atividade com seus alunos em uma praia de Aberdeen, após a leitura de texto de um arqueólogo que afirmava que a diferença entre claridade e embaraçamento não está na paisagem, mas no ato de percepção. Ingold propõe então a ideia de clima-mundo (weather-world).

We had rather to recognise that the ground on which we stood was not really a supporting platform upon which things rest but a zone of formative and transformative processes set in train through the interplay of wind, water and stone, within a field of cosmic forces such as those responsible for the tides. This became even more apparent as we lifted our glance to the surging breakers collapsing on the shore. What we saw were not objects and surfaces, but materials in motion. Raising our eyes still further we saw waves upon waves capped with foam, gradually panning out to the level expanse of the ocean, which in turn gave way to the unrelenting grey of the sky. Against this background, we could dimly make out the wheeling forms of seabirds, but we recognised them not as objects that moved, but as movements - oftentimes accompanied by sounds - that only resolved themselves into objective forms when they came to rest, perched on one of the many breakwaters that section the beach. In short, looking out to sea we saw a world in movement, in flux and becoming, a world of ocean and sky, a weather-world. We saw a world without objects (Ingold, 2011: 131). 
Para aprofundar tal discussão retorno a seguir ao contexto da ocorrência de neve em São Joaquim. Para acompanhar Tim Ingold deixo de lado o conceito de paisagem. Desse modo, pretendo buscar ver não a neve como um objeto em um cenário, tanto para visitantes como para moradores locais. Mas, ver a neve na interação com o vento, com a água da chuva e as pessoas em um mundo em movimento. A começar pelo climamundo do joaquinense.

\section{Os joaquinenses e a neve por Joaquim Anacleto}

Joaquim Anacleto Rodrigues Neto foi-me apresentado como escritor em São Joaquim. À procura de seus escritos logo conheci seu livro Memórias de um joaquinense. Procurei não em uma livraria, mas na própria cidade de São Joaquim, onde o livro é distribuído pelo autor e pelos financiadores da obra - agroindústrias de maçã, uma ferragem e a prefeitura do município. E, conheci o próprio autor durante trabalho de campo realizado na cidade. Quando o encontrei estava ocupado com a tradução de um de seus textos sobre o histórico da família para entregar a seu irmão que em viagem pela Europa se ocuparia da entrega a alguém na cidade de seus antepassados na Itália. Joaquim foi simpático e no dia seguinte me deu uma carona até seu sítio, onde mora atualmente.

Em certa medida, Joaquim Anacleto é expoente de uma parcela da população, uma classe social para usar um termo meio fora de moda, que substituiu os antigos fazendeiros no controle do poder local. Em sua maioria são descendentes desses antigos fazendeiros (terceira e quarta gerações), ex-soldados e tenentes do exército português que receberam parcelas de terras legadas pela coroa portuguesa no final século XVIII. Foram hábeis em acompanhar a modernização da agricultura nos anos 1960/70, se estabelecendo como produtores de maçã e muitos também como profissionais liberais, caso de Joaquim Anacleto, dentista de profissão.

Joaquim Anacleto, diferentemente de muitos descendentes dos antigos fazendeiros, é um homem que transpira a Cultura no sentido de cultivar as altas manifestações artísticas e eruditas da civilização. Anacleto é bisneto de um comerciante italiano que se estabeleceu em São Joaquim no século XIX e fez florescer na cidade as letras e as artes. Comerciante que levou para São Joaquim a "Família Martorano", responsável entre outras coisas, pelas principais pinturas da cidade e da região. Esta família é frequentemente lembrada nas conversas informais com moradores de São 
Joaquim com um quê de distinção. Existem também outras famílias de comerciantes, e certamente também os imigrantes e descendentes de imigrantes japoneses, que fazem parte da classe que detém o poder local. Mas, os Martorano expressam são em alguma medida os porta-vozes intelectuais desta classe.

Em Memórias de um joaquinense, estão publicados textos escritos para uma coluna do Jornal Mural. Os textos reunidos versam sobre os mais diversos temas relacionados a São Joaquim, particularmente fatos históricos marcantes da política, das histórias de famílias, dos clubes e sociedades, da economia local, entre outros. Joaquim Anacleto não é apenas o autor do livro, mas diretamente relacionado a muitos destes fatos, especialmente por ser figura política destacada, tendo sido prefeito em duas ocasiões. Como prefeito no início dos anos 1970 esteve presente em momentos importantes dos primeiros passos dados no sentido de desenvolver a produção de maçã. Retornou a prefeitura no início dos anos 1990. Cabe assinalar que pelo menos nos últimos quarenta anos alternaram-se por vários mandatos doutores (médicos, advogados, dentistas) na prefeitura de São Joaquim. Embora de partidos diferentes e pontuados por períodos com outros profissionais no comando da prefeitura, os mesmos mantém um fio comum na administração do município e no tipo de homem público.

Aposentado, Joaquim Anacleto coloca suas opiniões nos textos. Em um deles, não datado, mas possivelmente recente, bradava pelo não esquecimento de que os joaquinenses sabem lidar com a neve. Dizia ele, “(...) até parece que somos agora nordestinos, que não sabemos agir frente a uma onda de frio, puramente normal e nada fora dos padrões (Rodrigues Neto, 2010: 123)". Porém, em certo sentido, os joaquinenses se parecem com os nordestinos. Em ambos os lugares as fazendas de gado ou de grandes lavouras foram a base da sociabilidade ${ }^{17}$. O que os diferencia podem ser as festas, as comidas típicas, o sotaque, etc., mas, como podem ser diferentes em relação ao frio? Antes de prosseguir nesta discussão, vale conferir o argumento de Joaquim Anacleto (Rodrigues Neto, 2010: 122-123).

\section{NÃO SE FAZ MAIS NEVE COMO ANTIGAMENTE Terrorismo Branco, ou Histeria climática}

$\mathrm{Ah}$, os saudosos anos cinqüenta.

1957, a maior neve registrada em nossa história.

\footnotetext{
${ }^{17}$ Afrânio Garcia Jr (2002) traça um panorama sobre o debate em torno da velha plantation e as formas atuais de sociabilidade no campo.
} 


\begin{tabular}{|c|}
\hline 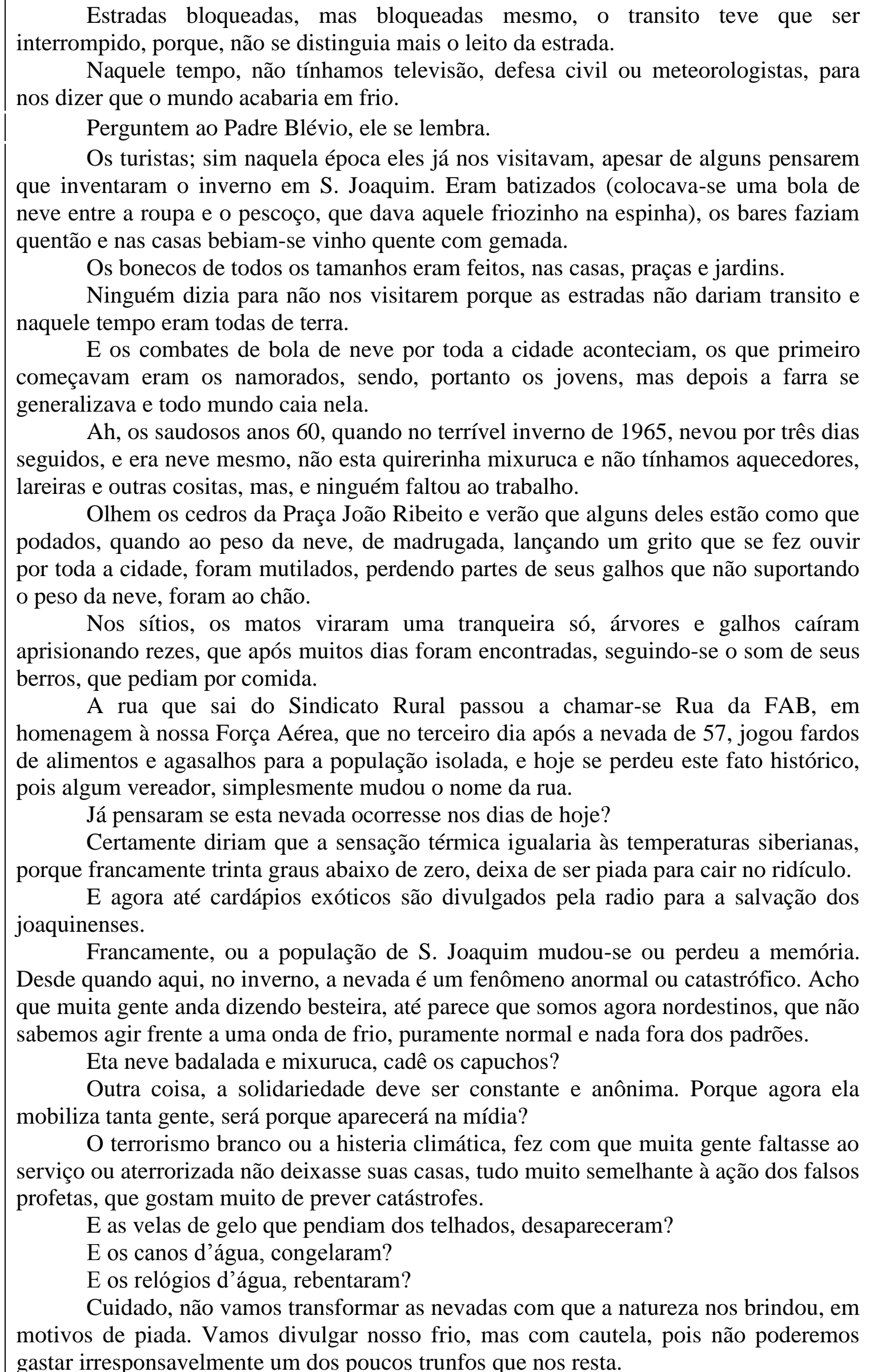 \\
\hline
\end{tabular}


Nossos conterrâneos ou familiares que moram longes, ligam desesperados: "O mundo iria acabar?", tivemos todos nós que acalmá-los, porque aqui, em toda a nossa história, ninguém morreu por falta de calor, principalmente o humano.

Como se vê, além de relembrar aos joaquinenses de que vivem em um lugar frio, o autor dá dicas de como se portar perante a neve. Não é preciso faltar ao trabalho, não é preciso ficar em casa e não se deve tornar as baixas temperaturas motivo de piada. A seguir, em outro texto, de abril de 1999, Joaquim Anacleto a particularidade do joaquinense. "Dizem que em matéria de futebol cada brasileiro é um técnico, o que equivale dizer, que todos dele entendemos. Agora que todo joaquinense entende de tempo, ah, isto é verdade (Rodrigues Neto, 2010: 117)".

\section{O JOAQUINENSE E A PREVISÃO DO TEMPO}

Dizem que em matéria de futebol cada brasileiro é um técnico, o que equivale dizer, que todos dele entendemos. Agora que todo joaquinense entende de tempo, ah, isto é verdade.

Nos dias atuais, temos a nossa disposição vasta tecnologia, para nos dizer se chove, faz sol, venta ou temos calmaria. Temos que banhar o pomar, mas como os defensivos são caros, consultamos primeiro o Coutinho (o meteorologista), a EPAGRI, ligamos no canal rural, nos plugamos na Internet, que traz em tempo real fotos do satélite americano. Direct TV e Sky oferecem canais do tempo, que 24 horas por dia nos dão a previsão do tempo e, nos guiando por ela, evitamos muitos gastos desnecessários. Mas eles acertam? Nem sempre!

Estamos nos aproximando do inverno, a época em que o joauqinense adora fazer previsões. Qual a origem dessa verdadeira mania? Sem dúvida, o maior orgulho nosso: "a neve". Se por ela tanto ansiamos é claro que teríamos que nos especializar em prevêla. E porque tanto por ela ansiamos? Está claro, porque a adoramos, porque temos que explicar ao turista ansioso por conhecê-la, se ele terá esta chance, porque se ela vier, esqueceremos tudo, ela deixará linda nossa cidade, cobrirá os buracos, eliminará a sujeira dos lotes mas cuidados e acima de tudo como acontece a cada inverno, sairemos do anonimato, apareceremos na imprensa nacional e a suprema glória acontece, o Cid Moreira com aquele vozeirão inconfundível diz: "neva na serra catarinense, desde a amanhã de hoje, cai neve em S. Joaquim, a cidade mais fria do Brasil, os termômetros marcam 1 grau abaixo de zero e a cidade enche-se de turistas de todo o Brasil, cai também um pouquinho de neve em Lages, cidadezinha próxima a S. Joaquim. Ah, Ah, Ah, querem satisfação maior?

Pois é, é por tudo isso e mais um pouco que nos especializamos em prever o tempo, especialmente se vai nevar.

As conversas quase sempre giram em torno dela, e nossos entendidos deixam de lado os especialistas e a vontade deixam suas previsões. Eis algumas:

- Para nevar tem que haver umidade, chover.

O Tio Duca (Belizário Pereira), agregado de meu avô, tinha uma previsão de chuva infalível - Se um burro velho que tinha na fazenda, entrasse correndo e orneando na mangueira e se espojasse três vezes, chuva na certa. 
Se chovia, tínhamos que observar os tico-ticos. Se eles estivessem alvorotados, em vez de voar estivessem no chão e ciscando de um lado para o outro, abra o guardachuva e tire o capote, neve na certa.

- Tem os que ficam olhando as chaminés observando para que lado sopra o vento. É o minuano? Então calce meias de lã a neve vai chegar.

Mas eu tenho uma previsão que julgo à mais segura: "Se estiver frio, chovendo, e a chuva for miúda, observe caro leitor como andam os passantes. Se eles andarem na rua, curvados no sentido Manoel Joaquim Pinto X Major Jacinto Goulart se tiverem guarda-chuva e andarem com ele abaixado e protegendo-se da chuva que cai inclinada vinda dos lados do minuano, pode apostar, vai nevar.

NOTA: Publicado na coluna Informal no Jornal Mural, edição 97 - $2^{\mathrm{a}}$ quinzena Abril de 1999.

$\mathrm{O}$ autor pontua os diferentes modos do joaquinense se relacionar com o tempo. Pelo que deixa entrever, muito mais confiáveis do que as previsões meteorológicas. Aqui, me parece estar bem clara a ideia que proponho baseado nos conceitos de Tim Ingold, de um clima-mundo (weathwe-world) do joaquinense. No texto abaixo, Joaquim Anacleto, desconfiado das previsões do tempo, narra sua experiência com a caída da neve. Sente a falta dos tico-ticos e do vento minuano, ambos companheiros da chegada da mesma. Depois de uma breve deitada, ouve o "suave murmúrio que nós joaquinenses conhecemos muito bem". A expectativa chega ao fim e o homem narra seu encontro com a neve. "Não hesito, jogo de lado as cobertas de lã, corro em direção à janela, abro as cortinas e maravilhado a vejo, lá está ela, teve dó de mim e da minha vigília”.

\section{AS NEVES DE AGOSTO}

(...)

Estou no sítio.

O fogão à lenha está com a chapa avermelhada e na lareira as brasas formadas pela queima dos nós de pinho e casca de pinheiro da boa que o kiko me mandou (Abel Vargas de Liz, mais conhecido por Ministro), espalham um calor modorrento que nos convida a uma cochilada. 19h30min. Nada de nevar.

Será que os modernos Nostradamus vão falhar.

Sei não, os tico-ticos não apareceram.

20h45min. Terminou o Jornal Nacional e nada de neve.

Estamos perdendo a oportunidade de inundar a cidade turistas neste fim de semana, mas os apresentadores de todos os telejornais insistem: Vai nevar.

$22 \mathrm{~h} 00 \mathrm{~min}$ - Muito frio, o vento é da costa (Vento que sopra vindo do mar), nada de minuano (vento oeste que traz a neve), nada de neve.

22h30min - Chega de esperar, vou dormir, antes desligar o computador (ainda não tenho internet no sítio), e dar uma última olhada no termômetro que está lá fora.

Putz, como diz meu irmão Ari, $6^{\circ}$ abaixo é a leitura.

Deito, começo a ler um livro de Agatha Christie, minha escritora favorita. 
Naquele silencio que só quem mora no sítio conhece, sinto que não escuto mais o barulho da chuva que caía, mas um suave murmúrio que nós joaquinenses conhecemos muito bem.

Não hesito, jogo de lado as cobertas de lã, corro em direção à janela, abro as cortinas e maravilhado a vejo, lá está ela, teve dó de mim e da minha vigília.

Neva aos capuchos, os homens acertaram.

Chama a Ana e a minha filha Ana Rita que já estavam dormindo. dormir.

Elas resmungam, não querem saber de capuchos, viram de lado e continuam a

$\mathrm{Eu}$, que estava esperando por ela desde as $18 \mathrm{~h} 40 \mathrm{~min}$, fico olhando como se nunca a tivesse visto.

Que linda, ainda mais aqui no sítio, tomara que ao acordar ainda a encontre. (...)

NOTA: Publicado no MURAL, edição nº 105, segunda quinzena de agosto de 1999.

De tempos em tempos os joaquinenses revivem experiências semelhantes. $\mathrm{O}$ entre que é surge aos demais habitantes do Brasil como uma experiência extraordinária no tempo de inverno. Como se vê na experiência narrada por Joaquim Anacleto, o murmúrio da neve é a própria neve. Ele a sente de dentro de sua casa e corre para conferir maravilhado. Acompanhando a sugestão de Ingold (2011), a neve não é alvo de percepção de seu corpo, mas está em uma experiência envolvente, uma atmosfera.

\section{Considerações finais}

O joaquinense abordado aqui a partir da experiência de Joaquim Anacleto é um personagem, dentre outros na Serra Catarinense, ao qual se evidencia que a maneira como se relaciona com o clima-mundo (weather-world) é importante a ser considerada na construção da identidade regional. Há outros personagens na mesma região que também estabelecem relações com o clima-mundo (weather-world), os quais são pertinentes reter a especificidade na elaboração de um quadro mais geral em uma pesquisa mais ampla.

De qualquer maneira, a ideia de clima-mundo (weather-world) apontada por Tim Ingold (2011) recentemente tem muito a contribuir a estudos que enfocam a construção de identidades regionais. Pois, permite lançar um olhar diferente sobre estas situações onde as pessoas buscam construir e reforçar determinadas particularidades em mundo já bastante globalizado. Um olhar que ajuda a colocar os aspectos "naturais" não apenas como exterioridade da identidade, mas também como componentes ativos. 


\section{Referências}

ANDERSON, Benedict. Comunidades Imaginadas: reflexiones sobre el origen y la difusion del nacionalismo. México: Fondo de Cultura Econômica, 1993.

BATESON, Gregory. "Form, Substance and Difference". In: BATESON, Gregory. Steps to an ecology of mind. Chicago/London: The University of Chicago Press, 2000. p. 454-471.

BHABHA, Homi. O local da cultura. Belo Horizonte: Ed. UFMG, 1998. 394 p.

INGOLD, Tim. The Perception of Environment: Essays on livelihood, dwelling and skill. London/ New York: Routledge, Taylor \& Francis e-Library, 2002.

INGOLD, Tim. Being Alive: essays on movement, knowledge and description. London/ New York: Routledge, Taylor \& Francis e-Library, 2011.

RODRIGUES NETO, Joaquim Anacleto. Memórias de um joaquinense. São Joaquim: Mural Produtos Gráficos, 2010.

THIESSE, Anne-Marie. La création des identités nationales - Europe XVIII $I^{e}-X X^{e}$ siécle. Paris: Éditions Du Seuil, 1999. 